\title{
Safety Assessment of Arsenic in Cosmetic Face-creams by Inductively Coupled Plasma Atomic Emission Spectrometer
}

\author{
Xijuan Tan ${ }^{1,2, *}$, Hong Liu ${ }^{3}$, Zhuming Wang ${ }^{1,2}$, Minwu Liu ${ }^{1,2}$ \\ ${ }^{1}$ Laboratory of Mineralization and Dynamics, Chang'an University, Xi'an, China \\ ${ }^{2}$ College of Earth Sciences and Land Resources, Chang'an University, Xi'an, China \\ ${ }^{3}$ Perkin Elmer Management (Shanghai) Co., Ltd, Shanghai, China
}

Email address:

tanxijuan@hotmail.com (Xijuan Tan), tanxijuan@chd.edu.cn (Xijuan Tan)

${ }^{*}$ Corresponding author

\section{To cite this article:}

Xijuan Tan, Hong Liu, Zhuming Wang, Minwu Liu. Safety Assessment of Arsenic in Cosmetic Face-creams by Inductively Coupled Plasma Atomic Emission Spectrometer. American Journal of Applied Chemistry. Vol. 7, No. 1, 2019, pp. 35-41. doi: 10.11648/j.ajac.20190701.14

Received: February 24, 2019; Accepted: April 2, 2019; Published: April 22, 2019

\begin{abstract}
This paper presented the arsenic determination in four different brands of cosmetic face-creams to provide valuable information on the safety levels for consumers. The cosmetic samples were decomposed by acidic digestion method and then taken for arsenic quantification using inductively coupled atomic emission spectrometry (ICP-AES). The digestion efficiency of acid mixtures including concentrated $\mathrm{HNO}_{3}, \mathrm{HNO}_{3}-\mathrm{HClO}_{4}, \mathrm{HNO}_{3}-\mathrm{H}_{2} \mathrm{O}_{2}$ and aqua regia was discussed in terms of digestion loss and time consumption. The ICP-AES analyzing results, with determination recoveries of $95.4 \% \sim 105.2 \%$ and relative standard deviations less than $3.0 \%(\mathrm{n}=5)$, revealed arsenic contents in the face-creams are in the ranges of $0.68 \sim 3.28 \mathrm{mg} \cdot \mathrm{kg}^{-1}$. Obviously, the arsenic contents in some of the studied brands exceed the maximum recommended value of $2.0 \mathrm{mg} \cdot \mathrm{kg}^{-1}$ set by China. These results lead to the conclusion that constant control of arsenic content in cosmetics should be seriously considered. The successful arsenic determination in cosmetic face-creams by digestion pattern of concentrated $\mathrm{HNO}_{3}$, with simplicity, higher efficiency, less reagent consumption and less analytical time well demonstrates the good analytical capability of this method, promising a great possibility for large batches of cosmetic toxic metal monitoring.
\end{abstract}

Keywords: Safety Assessment, Cosmetic Face-Creams, Arsenic Determination, Acidic Digestion, ICP-AES

\section{Introduction}

Since cosmetic civilization constituted a part in human daily lives [1,2], cosmetic products have boosted and been utilized directly for cleansing, beautifying, promoting attractiveness, or enhancing appearance [3]. Because of the ubiquitous nature of metals and metalloids, metal contamination occurs in cosmetic producing process [4] or comes from residential contaminants in natural raw materials $[5,6]$. Despite numerous controls in the manufacturing process, production according to the principles of Good Manufacturing Practice (GMP), and campaigns for cosmetic safe usage, toxic elements are still present even in the best quality products. Although the single use of a cosmetic containing a toxic element is not associated with obvious side effects, the prolonged human systematic exposure can rarely be completely excluded from skin allergy or cancer even at normal usage $[7,8]$. For these reasons, the health risk related to the usage of cosmetic has currently become an emerging public health problem [9], and the safety assessment of cosmetic products on inorganic elements has drawn great attention during the last decade $[10,11]$.

Arsenic, a redox inactive metalloid, is a notoriously hazardous inorganic element and presents almost everywhere as a major contaminant in our environment $[12,13]$. It can bind sulfydryl groups of proteins and deplete glutathione [14, 15]. Even low intakes of arsenic might cause arsenicosis over a long period such as 5-20 years with skin problems [16], and the long-term exposure to arsenic can lead to hyperpigmentation, keratosis, various types of cancer and vascular diseases [17-19]. To provide a protection level for consumers, cosmetic raw materials and terminal products 
need to pass through stringent quality control by local authorities. In China, the "technically avoidable" arsenic content in commercial cosmetics is limited as $2.0 \mu \mathrm{g} \cdot \mathrm{g}^{-1}$ [20]. Hence, a reliable and simple arsenic determination approach is of great necessary for routine cosmetic risk assessment.

Many laboratory-based analytical methods have been reported for arsenic determination, among which atomic absorption spectroscopy (AAS) is the commonly utilized protocol [21-25]. Atomic fluorescence spectroscopy (AFS) [5, 26], UV-vis spectrometric method [27], spectrophotometric technique [28] and anodic stripping voltammetry (ASV) [29] are also proposed to quantify arsenic levels in different matrices. Inductively coupled plasma (ICP), a spectroscopic source generated 100 years ago, has become an advanced and popular technique in elemental analysis due to low back ground emission intensities and small chemical interferences $[30,31]$. There are some works using ICP mass spectrometry (ICP-MS) for cosmetic arsenic determination [32, 33]. However, strict control of matrix effect is basically needed for ICP-MS analysis because of high sensitivity, which greatly challenges its application for inorganic element assay in organic samples [34]. The ICP atomic emission spectrometry (ICP-AES), a well-established multiple element analytical technique, shows advantages of accurateness, wide linear response range of 5-6 orders of magnitude, and only 1-2 $\mathrm{mL}$ of solution needed [35]. This technique is an attractive choice for minor and major inorganic element determination in various matrices [36-38]. By using ICP-AES, Alqadami et al. [39, 40] quantified arsenic levels in skin whitening cosmetics, and Capelli et al. [41] determined arsenic contents in cosmetic face-powders.

It's no doubt that sample treatment is crucial for trace element determination and complete sample decomposition is an essential prerequisite for accurate trace element analysis. Although microwave assisted acid digestion is promising for sample preparation with shorter digestion time and less reagent necessary, the application of this technique, to some degree, is limited by expensive instrument, unsuitable for large batches of sample analysis and potential safety problems [42]. Also, sample decomposition by dry ashing process apparently sacrifices analytical time [43]. Wet acidic digestion, the classic sample preparation method, has been extensively applied in cosmetic decomposition with different mixtures, including $\mathrm{HNO}_{3}-\mathrm{HCl}-\mathrm{HF}[33,44,45], \mathrm{HNO}_{3}-\mathrm{HCl}, \mathrm{HNO}_{3}-$ $\mathrm{H}_{2} \mathrm{O}_{2}$, $\mathrm{HF}$ [41], and $\mathrm{HNO}_{3}-\mathrm{H}_{2} \mathrm{O}_{2}-\mathrm{HF}[40,46]$. Currently, there has been no clear information of cosmetic decomposition capability of common acidic patterns. In this present work, the cosmetic digestion properties of concentrated $\mathrm{HNO}_{3}, \mathrm{HNO}_{3}$ $\mathrm{HClO}_{4}, \mathrm{HNO}_{3}-\mathrm{H}_{2} \mathrm{O}_{2}$ and aqua regia are examined for arsenic determination by ICP-AES. The accuracy, precision, limit of detection (LoD), repeatability, intra and inter-day reproducibility of this method are validated in detail. Finally, the potential applicability of this ICP-AES method with concentrated $\mathrm{HNO}_{3}$ digestion pattern is evaluated by quantifying arsenic levels in four different brands of cosmetic face-creams.

\section{Experimental}

\subsection{Reagents and Standard Solutions}

In this work, high-purity acids and high-purity water were used throughout sample digestion. The analytical grade acids $\left(\mathrm{HCl}\right.$ and $\mathrm{HNO}_{3}$ ), which were purchased from Sinopharm Chemical Reagent Co. Ltd, China, were purified by sub-boiling distillation in Teflon stills (Savillex DST-1000-PFA, USA) before usage. Deionized water passed through a Milli-Q water purification system (Millipore, Bedford, MA, USA) to produce high-purity water with the resistivity of $18.2 \mathrm{M} \Omega \cdot \mathrm{cm}$. In this work, $\mathrm{H}_{2} \mathrm{O}_{2}$ of guaranteed reagent grade (Sinopharm Chemical Reagent Co. Ltd, China) was used without further purification.

A $100 \mu \mathrm{g} \cdot \mathrm{g}^{-1}$ of stock arsenic solution in $2 \% \mathrm{HNO}_{3}(\mathrm{v} / \mathrm{v})$ was prepared from $1.0 \times 10^{3} \mu \mathrm{g} \cdot \mathrm{mL}^{-1}$ of arsenic standard solution (GSB04-1714-2004, the National Institute of standards and technology, China) by gravimetric dilution, and then kept in a refrigerator at $4{ }^{\circ} \mathrm{C}$. All the experimental solutions and calibration standards were prepared by one-stage gravimetric dilution from the above stock standard solution.

\subsection{Instrumental Apparatus}

The Thermofisher Scientific iCAP 6300 radial ICP-AES instrument with the RF-Generator of $27.12 \mathrm{MHz}$ (Waltham, MA, USA) is used for arsenic determination. The ICP-AES apparatus is equipped with a concentric nebulizer for samples injection, a cyclonic spray chamber, a standard quartz torch and a charge-injection device detector (CID 86). The element measurements are accomplished in the axial view mode with the recommended observation altitude of $12 \mathrm{~mm}$, and all the data collection are achieved by using iTEVA software package with continuous scanning mode and the maximum integration time of $30 \mathrm{~s}$.

\subsection{Sample Handling for ICP-AES}

All the labware were boiled using 50\% nitric acid (v/v) for $24 \mathrm{hr}$, followed by high-purity water rinse. Four parallel face-cream cosmetic samples approximately $0.5 \mathrm{~g}$ were weighed in screw-top Savillex ${ }^{\circledR}$ beakers. To remove ethanol molecule, the samples were heated at $80{ }^{\circ} \mathrm{C}$ until no gas emission. After the samples in the beakers returned to ambient temperature, $10 \mathrm{~mL}$ of $\mathrm{HNO}_{3}-\mathrm{HClO}_{4}$ (v/v: 3+1, Branch A), $4.0 \mathrm{~mL}$ of aqua regia (Branch $\mathrm{B}), 5.0 \mathrm{~mL}$ of $\mathrm{HNO}_{3}-\mathrm{H}_{2} \mathrm{O}_{2}(\mathrm{v} / \mathrm{v}$ : 2.5+2.5, Branch C) and $3.5 \mathrm{~mL}$ of $\mathrm{HNO}_{3}$ (Branch D) were carefully added, respectively. For the sample branch fortified with $\mathrm{HNO}_{3}-\mathrm{HClO}_{4}$ mixture, the samples were aged overnight before the subsequent procedures. Having all the branches been heated in the sealed beakers at $120^{\circ} \mathrm{C}$ for $3 \mathrm{hr}$, the samples were evaporated until incipient dryness. For Branch A and Branch $\mathrm{B}, 1.0 \mathrm{~mL}$ of $\mathrm{HNO}_{3}$ was added twice to eliminate the excess $\mathrm{HCl}$ and $\mathrm{HClO}_{4}$. Finally, $3.0 \mathrm{~mL}$ of $5 \%$ $\mathrm{HNO}_{3}$ were then introduced into all the four beakers. Thereafter, the sample solutions were continuously heated until bright color obtained, and then transferred into a 10.0 
mL-calibrated tube. The digested samples were centrifuged at $4500 \mathrm{rpm}$ for $5.0 \mathrm{~min}$, and suitable aliquots from the clear supernatant were directly taken for arsenic determination by ICP-AES.

\subsection{Spiking Procedures}

The spiked cosmetic samples were prepared as follows: 1) known quantities of arsenic standard solutions were added into the artificial sample mainly including glycerine and vaseline; 2) the homogenous samples were digested using $\mathrm{HNO}_{3}-\mathrm{H}_{2} \mathrm{O}_{2}$ (v/v: 2.5+2.5), $\mathrm{HNO}_{3}-\mathrm{HClO}_{4}$ (v/v: 3+1), aqua regia and concentrated $\mathrm{HNO}_{3}$ as described above. To evaluate the matrix effect of the cosmetic samples, quantified arsenic standard solution was fortified in the artificial samples with arsenic content of $10 \mathrm{mg} \cdot \mathrm{kg}^{-1}$, and then the arsenic levels were measured by ICP-AES using spiked-recovery method. By taking the overall repeatability of the ICP-AES detector into consideration, the calibration procedures were carried out on three different days. The method precision was tested by measuring the repeatability for arsenic determination in standard solutions and differently digested cosmetic samples with the relative standard deviations (RSDs) studied.

\section{Results and Discussion}

\subsection{Experimental Condition Optimization for Arsenic Determination}

In this work, the effects of experimental conditions for arsenic determination by ICP-AES including output power, gas (Ar) flow rate of coolant/auxiliary/nebulizer, flow rate of sampling and pump stable time were tested.

Figure 1 clearly shows the spectroscopic signal increases with increasing output power from 750 to $1150 \mathrm{~W}$, while shows slight decrement from 1200 to $1400 \mathrm{~W}$ (Herein, the concentration of studied arsenic is $20 \mu \mathrm{g} \cdot \mathrm{g}^{-1}$ ). Considering a better precision and repetitiveness, $1150 \mathrm{~W}$ of output power is chosen as the optimum value in this work. To enhance the sensitivity and precision of arsenic quantification, the flow rate of coolant gas is studied within $10 \sim 15 \mathrm{~L} \cdot \mathrm{min}^{-1}$. As shown in Figure 2, the spectroscopic signal clearly increases with coolant gas flow rate up to $12 \mathrm{~L} \cdot \mathrm{min}^{-1}$ and then declines. Hence, $12 \mathrm{~L} \cdot \mathrm{min}^{-1}$ of coolant Ar is optimal. The result of auxiliary gas flow rate between 0.1 and $0.7 \mathrm{~L} \cdot \mathrm{min}^{-1}$ reveals that this parameter shows no obvious effect on the spectroscopic signal lower than $0.5 \mathrm{~L} \cdot \mathrm{min}^{-1}$. Herein, 0.4 $\mathrm{L} \cdot \mathrm{min}^{-1}$ is used through the subsequent experiments. Considering the stability and efficiency of the reagents, 0.7 $\mathrm{L} \cdot \mathrm{min}^{-1}$ of nebulizer $\mathrm{Ar}, 2.0 \mathrm{~mL} \cdot \mathrm{min}^{-1}$ of peristaltic pump and $5.0 \mathrm{~s}$ of pump stable time are selected in the subsequent work.

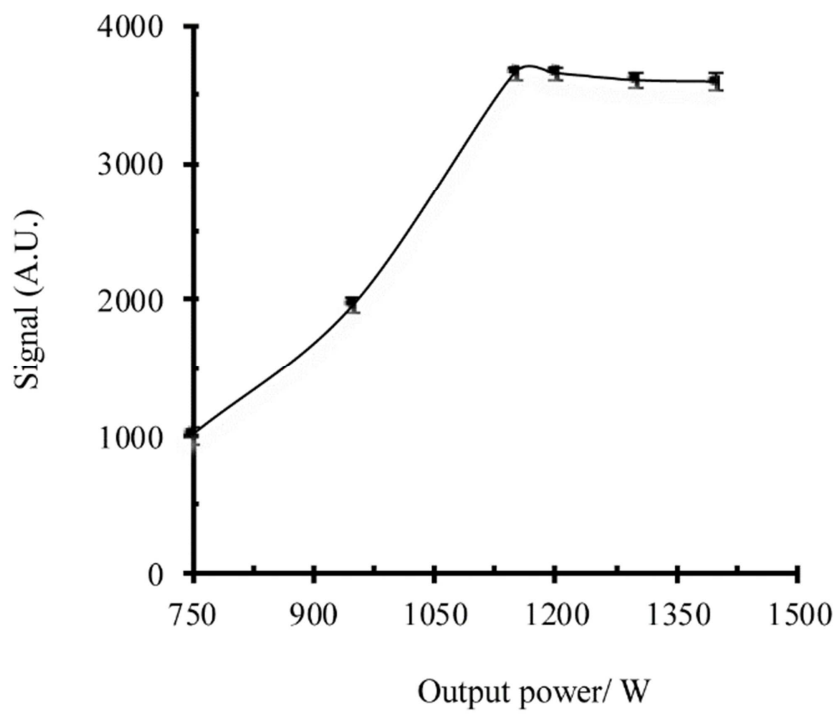

Figure 1. The relationship between arsenic spectroscopic signal and the output power of ICP-AES.

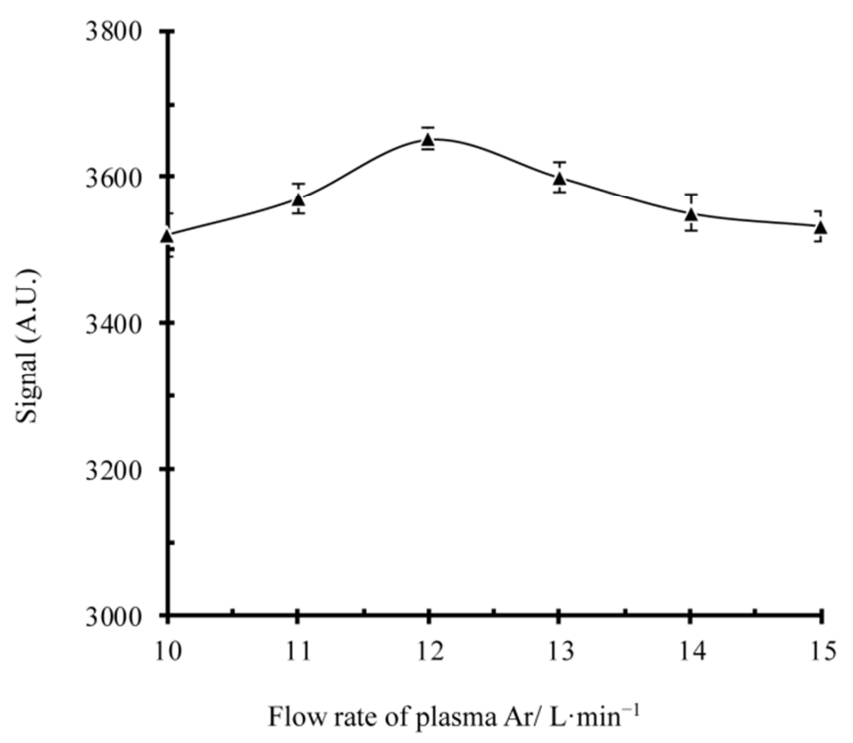

Figure 2. The influence of plasma Ar flow rate on arsenic spectroscopic signal of ICP-AES.

Table 1. Arsenic contents in the SRM material of GBW 09303 by ICP-AES for different acidic digestion patterns $(n=5)^{a}$.

\begin{tabular}{|c|c|c|c|c|c|}
\hline Digestion pattern & Arsenic found $^{\mathrm{b}} \mu \mathrm{g} \cdot \mathrm{g}^{-1}$ & RSD \% & Recovery \% & Content in SRM $\mathrm{mg} \cdot \mathrm{kg}^{-1}$ & Digestion loss \% \\
\hline $\mathrm{HNO}_{3}-\mathrm{HClO}_{4}$ & 17.33 & 2.5 & 104.4 & $6.80 \pm 0.17$ & 5.8 \\
\hline Aqua regia & 17.25 & 2.8 & 105.0 & $6.74 \pm 0.19$ & 6.6 \\
\hline $\mathrm{HNO}_{3}-\mathrm{H}_{2} \mathrm{O}_{2}$ & 17.12 & 1.8 & 101.2 & $7.01 \pm 0.12$ & - \\
\hline Concentrated $\mathrm{HNO}_{3}$ & 17.21 & 1.3 & 99.7 & $7.24 \pm 0.09$ & - \\
\hline
\end{tabular}

${ }^{\text {a }}$ The referred value of arsenic for GBW 09303 is $7.22 \pm 0.20 \mathrm{mg} \cdot \mathrm{kg}^{-1}$;

${ }^{\mathrm{b}}$ A standard arsenic solution of $10 \mu \mathrm{g} \cdot \mathrm{g}^{-1}$ is added in the SRM material.

\subsection{Accuracy Study of the Acidic Digestion Method}

In this present work, the SRM cosmetic material of GBW
09303 was used in the accuracy study for the digestion patterns. After the SRM materials were decomposed as described before, the arsenic levels were quantified by 
ICP-AES, with results given in Table 1. Obviously, the recoveries for arsenic determination in the SRM sample range from $99.7 \%$ to $105 \%$ with RSDs less than $3.0 \%(n=5)$, demonstrating the good accuracy of this proposed ICP-AES method for arsenic quantification. As shown in Table 1, arsenic contents from digestion patterns of $\mathrm{HNO}_{3}-\mathrm{HClO}_{4}$ $\left(6.80 \pm 0.17 \mathrm{mg} \cdot \mathrm{kg}^{-1}\right)$ and aqua regia $\left(6.74 \pm 0.19 \mathrm{mg} \cdot \mathrm{kg}^{-1}\right)$ show significant difference comparing to the referred value of $7.22 \pm 0.20 \mathrm{mg} \cdot \mathrm{kg}^{-1}$. However, the arsenic level for this SRM sample digested by acid patterns $\mathrm{HNO}_{3}-\mathrm{H}_{2} \mathrm{O}_{2}(7.01 \pm 0.12$ $\left.\mathrm{g} \cdot \mathrm{kg}^{-1}\right)$ or concentrated $\mathrm{HNO}_{3}\left(7.24 \pm 0.02 \mathrm{mg} \cdot \mathrm{kg}^{-1}\right)$ agrees well with the referred value, revealing the acceptable accuracy for the two digestion methods.

\subsection{Precision and Repeatability Study}

Here, the method's precision was evaluated from the RSDs of repetitive measurements carried out in solutions containing the analyte. In this current work, the RSDs for arsenic determination range from $0.1 \%$ to $3.0 \%$, and the variations of the RSDs are in the same range for all diluted and digested samples tested.

The repeatability of this approach was also investigated. Herein, the low, medium and high concentrations of arsenic (5, $\left.20, \quad 40 \mu \mathrm{g} \cdot \mathrm{g}^{-1}\right)$ were repetitively quantified in three consecutive days. The RSDs were studied, giving the RSDs for intra- and inter-day measurements were less than $4.0 \%$ (n $=5$ ). Obviously, the proposed method shows a good applicability for arsenic determination.

\subsection{Characteristics of the Analytical Performance for Arsenic Determination}

Under the optimum experimental conditions, a series of arsenic standard solutions was pumped into the concentric nebulizer with the atomic emission intensities for arsenic at $193.759 \mathrm{~nm}$ recorded. Results reveal the spectroscopic signal regularly increases with increasing arsenic concentration in range of $1.0 \sim 40 \mu \mathrm{g} \cdot \mathrm{g}^{-1}$. By plotting spectroscopic signal versus arsenic concentration (seen in Figure 3), the linear regression result shows that the calibration equation follows $A$ $=18.61 C_{\text {arsenic }}$ with $R^{2}=0.999$. The LoD, which is defined as $3 \mathrm{~S} / \mathrm{k}$ (the $\mathrm{S}$ is the standard deviation of twenty replicate analysis of the blank, and $\mathrm{k}$ is the slope of the calibration equation) [43] is $0.10 \mu \mathrm{g} \cdot \mathrm{g}^{-1}$ for arsenic. Additionally, the RSDs $(\mathrm{n}=5)$ for arsenic determination for 5, 20 and $40 \mu \mathrm{g} \cdot \mathrm{g}^{-}$
${ }^{1}$ are $2.34 \%, 1.35 \%$ and $1.17 \%$, respectively.

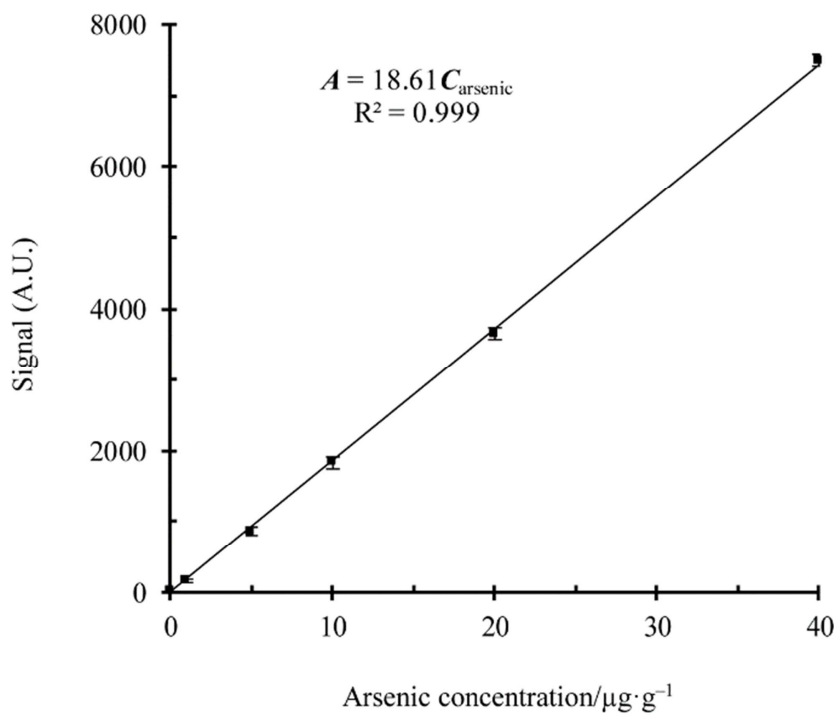

Figure 3. The calibration graph of spectroscopic signal of ICP-AES versus arsenic concentration.

To verify the matrix effect of cosmetic samples, arsenic standard solutions with final content of $15 \mathrm{mg} \cdot \mathrm{kg}^{-1}$ were added to the artificial cosmetic sample with recovery studied. Result shows the contents of arsenic are $15.12 \pm 0.3 \mathrm{mg} \cdot \mathrm{kg}^{-1}$ and the determination recoveries are between $96.3 \%$ and $103.4 \%(n=5)$, which reveals that the cosmetic matrix effect can be neglected in this work.

\subsection{Comparison of Different Cosmetic Digested Methods for Arsenic Quantification}

As seen in Table 1, the arsenic levels in GBW 09303 by digestion patterns of $\mathrm{HNO}_{3}-\mathrm{HClO}_{4}$ and aqua regia show obvious differences with the referred value of $7.22 \pm 0.20$ $\mathrm{mg} \cdot \mathrm{kg}^{-1}$. To further evaluate the digestion methods, an artificial cosmetic sample spiked with $10 \mathrm{mg} \cdot \mathrm{kg}^{-1}$ of arsenic was tested. Following the preparation procedures, the samples were quantified by ICP-AES with the recoveries examined. By spiked-recovery method, the determination results are listed in Table 2.

Table 2. Comparison of different acidic digestion methods for arsenic analysis in spiked cosmetic samples ${ }^{a}$.

\begin{tabular}{|c|c|c|c|c|c|c|c|}
\hline Digestion pattern & Added/Found $\mu \mathrm{g} \cdot \mathrm{g}^{-1}$ & RSD \% & Recovery \% & Content $\mathbf{m g} \cdot \mathbf{k g}^{-1}$ & $\begin{array}{l}\text { Digestion } \\
\text { loss \% }\end{array}$ & $\begin{array}{l}\text { Reagent } \\
\text { need } / \mathrm{mL}\end{array}$ & $\begin{array}{l}\text { Digestion } \\
\text { time/hr }\end{array}$ \\
\hline \multirow{2}{*}{$\mathrm{HNO}_{3}-\mathrm{HClO}_{4}$} & $5.0 / 15.23$ & 2.7 & 104.4 & $9.25 \pm 0.25$ & 7.5 & \multirow{2}{*}{10.0} & \multirow{2}{*}{$>15$} \\
\hline & $10.0 / 20.51$ & 2.5 & 105.2 & $9.24 \pm 0.23$ & 7.6 & & \\
\hline \multirow{2}{*}{ Aqua regia } & $5.0 / 15.15$ & 2.9 & 103.3 & $8.86 \pm 0.26$ & 11.4 & \multirow{2}{*}{4.0} & \multirow{2}{*}{$\sim 12$} \\
\hline & $20.0 / 30.58$ & 2.0 & 102.9 & $8.77 \pm 0.18$ & 12.3 & & \\
\hline \multirow{2}{*}{$\mathrm{HNO}_{3}-\mathrm{H}_{2} \mathrm{O}_{2}$} & $5.0 / 15.05$ & 2.6 & 101.2 & $9.80 \pm 0.25$ & - & \multirow{2}{*}{5.0} & \multirow{2}{*}{$\sim 8.0$} \\
\hline & $15.0 / 25.37$ & 2.5 & 102.4 & $9.88 \pm 0.24$ & - & & \\
\hline \multirow{2}{*}{ Concentrated $\mathrm{HNO}_{3}$} & $10.0 / 19.98$ & 1.8 & 99.6 & $10.08 \pm 0.18$ & - & \multirow{2}{*}{3.5} & \multirow{2}{*}{$\sim 6.5$} \\
\hline & $15.0 / 24.99$ & 1.5 & 100.1 & $9.98 \pm 0.15$ & - & & \\
\hline
\end{tabular}

${ }^{a}$ The fortified arsenic concentration in the artificial cosmetic sample is $10 \mathrm{mg} \cdot \mathrm{kg}^{-1}$. 
Clearly, the arsenic determination recoveries from $97.0 \%$ to $104.4 \%$ with $\mathrm{RSDs}<3.0(\mathrm{n}=5)$ reconfirm the capability of this proposed approach for cosmetic arsenic quantification. It's also apparent that the arsenic contents by digestion patterns (aqua regia and $\mathrm{HNO}_{3}-\mathrm{HClO}_{4}$ ) are about 7.5-12.3\% lower than the fortified value, which might ascribe to the erasing procedure of $\mathrm{HCl}$ or $\mathrm{HClO}_{4}$ prior to quantification. However, the results for $\mathrm{HNO}_{3}$ and $\mathrm{HNO}_{3}-\mathrm{H}_{2} \mathrm{O}_{2}$ digestion methods show great agreement with the spiked arsenic content of $10 \mathrm{mg} \cdot \mathrm{kg}^{-1}$. Additionally, Table 2 shows that the digestion pattern of $\mathrm{HNO}_{3}-\mathrm{H}_{2} \mathrm{O}_{2}$ mixture requires reagent volume of $5.0 \mathrm{~mL}$ and approximate $8.0 \mathrm{hr}$ of digestion time, while the concentrated $\mathrm{HNO}_{3}$ acid pattern only needs $3.5 \mathrm{~mL}$ with digestion time of $6.5 \mathrm{hr}$. Hence, by taking the reagent consumption, digestion time and simplicity into consideration, the concentrated $\mathrm{HNO}_{3}$ as the extracting reagent for arsenic is the most suitable digestion pattern in this current work.

\subsection{Cosmetic Face-cream Arsenic Analysis}

To evaluate the analytical applicability of this proposed approach using $\mathrm{HNO}_{3}$ digestion, arsenic levels in real cosmetic face-cream samples (brand Cloud-x, Aloe-vera, Prestige and Guerisson) from local market were determined. The results in Table 3 show that the contents of arsenic in the studied cosmetic samples are within the ranges of 0.68 and $3.28 \mathrm{mg} \cdot \mathrm{kg}^{-1}$. Clearly, although being well below the maximum value in brands of Aloe-vera, Prestige and Guerisson, the arsenic concentration in brand of Cloud-x is higher than the limited value of $2.0 \mathrm{mg} \cdot \mathrm{kg}^{-1}$ [20]. Hence, consumers should be more careful about the potential health problems from cosmetic products. The determination recoveries for arsenic in cosmetic samples range from $95.4 \%$ to $103.5 \%$ with the RSDs less than $3.0 \%(\mathrm{n}=5)$, demonstrating the proposed method can successfully assay arsenic levels in cosmetic samples.

Table 3. The determining results of arsenic contents in cosmetic face-creams by ICP-AES using spiked-recovery method ${ }^{a}$.

\begin{tabular}{|c|c|c|c|c|c|}
\hline Cosmetic brand $^{b}$ & Added $\mu g \cdot g^{-1}$ & Found $\mu \mathrm{g} \cdot \mathrm{g}^{-1}$ & RSD \% & Recovery \% & Content in cosmetics $\mathrm{mg} \cdot \mathrm{kg}^{-1}$ \\
\hline Cloud-x & 3.0 & 6.25 & 1.8 & 99.1 & $3.28 \pm 0.05$ \\
\hline Aloe-vera & 5.0 & 5.86 & 2.7 & 103.5 & $0.68 \pm 0.02$ \\
\hline Prestige & 7.0 & 8.38 & 2.2 & 95.4 & $1.70 \pm 0.03$ \\
\hline Guerisson & 5.0 & 6.40 & 2.5 & 101.6 & $1.31 \pm 0.08$ \\
\hline
\end{tabular}

${ }^{a}$ Each result is the average of five parallel determinations;

${ }^{\mathrm{b}}$ The studied sample size of cosmetic face-creams is $0.5 \mathrm{~g}$.

\section{Conclusion}

In this paper, four acidic digestion patterns including concentrated $\mathrm{HNO}_{3}, \mathrm{HNO}_{3}-\mathrm{HClO}_{4}, \mathrm{HNO}_{3}-\mathrm{H}_{2} \mathrm{O}_{2}$ and aqua regia for arsenic determination in cosmetic face-creams are studied detailly. Results show that concentrated $\mathrm{HNO}_{3}$ seems to be the most suitable extract agent with satisfactory digestion efficiency and less time consumption. The ICP-AES analysis of arsenic levels in four brands of commercial cosmetic face-creams presents determination recoveries ranging from $95.4 \%$ to $103.5 \%$ and $\mathrm{RSDs}<3.0 \%$ $(\mathrm{n}=5)$, which obviously demonstrates the reliability and good capability of this proposed approach for arsenic determination. The merits of simplicity, higher efficiency, less reagent consumption and less analytical time well promise the possibility of this acidic digestion method in arsenic quality control for large batches of commercial cosmetic products.

\section{Acknowledgements}

We appreciate constructive comments from anonymous reviewers and the editor. We also gratefully acknowledge the instrumental support from Laboratory of Mineralization and Dynamics, Chang'an University. The work was financially supported by the Fundamental Research Funds for the Central Universities of Chang'an University, China (No. 310827161008 and No. 300102278201). The corresponding author also thanks the financial support from the China Scholarship Council (CSC) during her study in Switzerland.

\section{Conflict of Interests}

The authors declare that there is no conflict of interests regarding the publication of this paper.

\section{References}

[1] B. Bocca, A. Pino, A. Alimonti, and G. Forte (2014) Toxic metals contained in cosmetics: A status report. Regulatory Toxicology and Pharmacology 68, 447-467.

[2] V. J. Brown (2013) Metals in lip products: A cause for concern. Environmental Health Perspectives 121, 196.

[3] M. Aslam, S. S. Davis and M. A. Healy (1979) Heavy metals in some Asian medicines and cosmetics. Public Health 93, 274-284.

[4] E. L. Sainio, R. Jolanki, E. Hakala, and L. Kanerva (2000) Metals and arsenic in eye shadows. Contact Dermatitis 42, $5-10$.

[5] J. G. Ayenimo, A. M. Yusuf, A. S. Adekunle, and O. W. Makinde (2010) Heavy metal exposure from personal care products. Bulletin of Environmental Contamination and Toxicology 84, 8-14.

[6] R. S. Zulaikha, S. N. Syed Ismail, and S. M. Praveena (2015) Hazardous ingredients in cosmetics and personal care products and health concern: A review. Public Health Research 5, 7-15. 
[7] H. Ullah, S. Noreen, Fozia, A. Rehman, A. Waseem, S. Zubair, M. Adnan, and I. Ahmad (2017) Comparative study of heavy metals content in cosmetic products of different countries marketed in Khyber Pakhtunkhwa, Pakistan. Arabian Journal of Chemistry 10, 10-18.

[8] A. D. Kligerman, and A. H. Tennant (2007) Insights into the carcinogenic mode of action of arsenic. Toxicology and Applied Pharmacology 222, 281-288.

[9] J. X. Pereira, and T. C. Pereira (2018) Cosmetics and its health risks. Global Journal of Medical Research 18, 63-66.

[10] K. Prasertboonyai, B. Liawraungrath, T. Pojanakaroon, and S. Liawraungrath (2016) Mercury(II) determination in commercial cosmetics and local Thai traditional medicines by flow injection spectrophotometry. International Journal of Cosmetic Science 38, 68-76.

[11] F. A. Ababneh, and I. F. Al-Momani (2018) Assessments of toxic heavy metals contamination in cosmetic products. Environmental Forensics 19, 134-142.

[12] J. Y. Chung, S. D. Yu, Y. S. Hong, (2014) Environmental source of arsenic exposure. Journal of Preventive Medicine \& Public Health 47, 253-257.

[13] P. B. Tchounwou, A. K. Patlolla, and J. A. Centeno, (2003) Carcinogenic and systemic health effects associated with arsenic exposure-A critical review. Toxicologic Pathology 31, $575-588$.

[14] K. Jomova, and M. Valko (2011) Advances in metal-induced oxidative stress and human disease. Toxicology 283, 65-87.

[15] V. Pachauri, and S. J. S. Flora (2010) Chelation in metal intoxication. International Journal of Environmental Research and Public Health 7, 2745-2788.

[16] T. Rujiralai, N. Juansai, and W. Cheewasedtham (2018) Arsenic determination in soils and hair from schools in past mining activity areas in Ron Phibun district, Nakhon Si Thammarat province, Thailand and relationship between soil and hair arsenic. Chemical Paper 72, 381-391.

[17] H. J. Sun, B. Rathinasabapathi, B. Wu, J. Luo, L. P. Pu, L. Q. $\mathrm{Ma}$, (2014) Arsenic and selenium toxicity and their interactive effects in humanity: An overview. Environment International $69,148-586$.

[18] P. Bhattacharjeea, D. Chatterjeea, K. Singhb, and A. Giri (2013) Systems biology approaches to evaluate arsenic toxicity and carcinogenicity: An overview. International Journal of Hygiene and Environmental Health 216, 574-586.

[19] H. Gibb, C. Haver, D. Gaylor, S. Ramasamy, J. S. Lee, D. Lobdell, T. Wade, C. Chen, P. White, and R. Sams, (2011) Utility of recent studies to assess the National Research Council 2001 estimates of cancer risk from ingested arsenic. Environmental Health Perspective 119, 284-290.

[20] Ministry of Health of the People's Republic of China. (2015) Safety and technical standards for cosmetics, Beijing, China, 166.

[21] T. Mohammed, E. Mohammed, and S. Bascombe, (2017) The evaluation of total mercury and arsenic in skin bleaching creams commonly used in Trinidad and Tobago and their potential risk to the people of the Caribbean. Journal of Public Health Research 6, 184-189.
[22] P. Olmedo, A. Pla, A. F. Hernández, F. Barbier, L. Ayouni, and F. Gil (2013) Determination of toxic elements (mercury, cadmium, lead, tin and arsenic) in fish and shellfish samples. Environment International 59, 63-72.

[23] R. R. Rasmussen, Y. Qian, and J. J. Sloth (2013) SPE HG-AAS Method for the determination of inorganic arsenic in rice--results from method validation studies and a survey on rice products. Analytical and Bioanalytical Chemistry 405, 7851-7857.

[24] N. R. Cha, J. K. Lee, Y. R. Lee, H. J. Jeong, H. K. Kim, and S. Y. Lee (2010) Determination of iron, copper, zinc, lead, nickel and cadmium in cosmetic matrices by flame atomic absorption spectroscopy. Analytical Letters 43, 259-268.

[25] W. Holak (1969) Gas-sampling technique for arsenic determination by atomic absorption spectrophotometry. Analytical Chemistry 41, 1712-1713.

[26] C. X. Xu, W. S. Lin, H. M. Hu, and L. F. Cai (2013) Determination of arsenic and mercury in cosmetics by atomic fluorescence method with graphite furnace digestion. China Surfactant Detergent \& Cosmetics 43, 78-80.

[27] R. Domínguez-González, L. González Varela, and P. Bermejo-Barrera (2014) Functionalized gold nanoparticles for the detection of arsenic in water. Talanta 118, 262-269.

[28] M. A. Tahir, H. Rasheed, and A. Malana (2012) Method development for arsenic analysis by modification in spectrophotometric technique. Drinking Water Engineering and Science 1, 195-201.

[29] L. H. Wang, and H. J. Tien (1994) Determination of lead, arsenic and mercury in cosmetic formulations at modified electrodes. International Journal of Cosmetic Science 16, 29-38.

[30] D. J. Butcher (2010) Advances in inductively coupled plasma optical emission spectrometry for environmental analysis. Instrumentation Science \& Technology 38, 458-469.

[31] R. Rezaaiyaan, and G. M. Hieftje (1985) Analytical characteristics of a low-flow, low-power inductively coupled plasma. Analytical Chemistry 57, 412-415.

[32] S. Y. Ng, F. Dewi, J. Wang, L. P. Sim, R. Y. C. Shin, and T. K. Lee (2015). Development of a cosmetic cream certified reference material: Certification of lead, mercury and arsenic mass fractions in cosmetic cream. International Journal of Mass Spectrometry 389, 59-65.

[33] N. M. Hepp (2015) Determination of arsenic, chromium, lead, manganese, and mercury in certifiable color additives by inductively coupled plasma/mass spectrometry. Journal of AOAC INTERNATIONAL 98, 160-164.

[34] C. Agatemor, and D. Beauchemin (2011) Matrix effects in inductively coupled plasma mass spectrometry: A review. Analytica Chimica Acta 706, 66-83.

[35] M. A. Almessiere, R. Altuwiriqi, M. A. Gondal, R. K. Aldakheel, and H. F. Alotaibi (2018) Qualitative and quantitative analysis of human nails to find correlation between nutrients and Vitamin D deficiency using LIBS and ICP-AES. Talanta 185, 61-70.

[36] R. Saidalavi, A. Hashim, K. B. Kishor, P. K. Leena, and P. Adake (2017) Analysis of lead and arsenic in cosmetics and assessment of students awareness about cosmetic toxicity. International Journal of Basic \& Clinical Pharmacology 6, 1426-1430. 
[37] A. M. Fioroto, and P. V. Oliveira (2017) Microwave-assisted digestion with a single reaction chamber for mineral fertiliser analysis by inductively coupled plasma optical emission spectrometry. Spectroscopy Letters 50, 550-556.

[38] C. Cui, B. Hu, B. Chen, and M. He (2013) Ionic liquid-based magnetic solid phase extraction coupled with inductively coupled plasma-optical emission spectrometry for the determination of $\mathrm{Cu}, \mathrm{Cd}$, and $\mathrm{Zn}$ in biological samples. Journal of Analytical Atomic Spectrometry 28, 1110-1117.

[39] A. A. Alqadami, M. A. Abdalla, Z. A. Alothman, and K. Omer (2013) Application of solid phase extraction on multiwalled carbon nanotubes of some heavy metal ions to analysis of skin whitening cosmetics using ICP-AES. International Journal of Environmental Research and Public Health 10, 361-374.

[40] A. A. Alqadami, M. Naushad, A. M. Abulhassan, M. R. Khan, Z. A. Alothman, S. M. Wabaidur, and A. A. Ghfar (2017) Determination of heavy metals in skin-whitening cosmetics using microwave digestion and inductively coupled plasma atomic emission spectrometry. IET Nanobiotechnology 11, 597-603.

[41] C. Capelli, D. Foppiano, G. Venturelli, E. Carlini, E. Magi, and C. Ianni (2014) Determination of arsenic, cadmium, cobalt, chromium, nickel, and lead in cosmetic face-powders: Optimization of extraction and validation. Analytical Letters 47, 1201-1209.

[42] A. Agazzi, and C. Pirola (2000) Fundamentals, methods and future trends of environmental microwave sample preparation. Microchemical Journal 67, 337-341.

[43] I. O. Akinyele, and O. S. Shokunbi, (2015) Comparative analysis of dry ashing and wet digestion methods for the determination of trace and heavy metals in food samples. Food Chemistry 173, 682-684.

[44] O. Al-Dayel, J. Hefne, and T. Al-Ajyan (2011) Human exposure to heavy metal from cosmetics. Oriental Journal of Chemistry 27, 1-11.

[45] S. Y. I. Issa, R. A. Maguid, and M. K. AlMazroua (2016) Determination of toxic contents and metals in different cosmetic products in the Arabian market. Journal of Environmental and Analytical Toxicology 6, 1-5.

[46] E. A. M. Farrag, M. H. E. A. Sei'Leek, and M. I. A. Alsayyed (2015) Study of heavy metals concentration in cosmetics purchased from Jordan markets by ICP-MS and ICP-OES. Aes Bioflux 7, 383-394. 